2019 Global Fashion Management Conference at Paris Proceedings:614-625 (July 2019) https://doi.org/10.15444/GFMC2019.06.03.02

\title{
SAVORING THE PRODUCT: A LOOK AT THE IMPACT OF AI ON PRE AND POST PURCHASE SATISFACTION
}

\author{
Sharmin Attaran, Bryant University, United States ${ }^{1}$ \\ Mohsen Attaran, CSUB, United States \\ Diane Kirkland, CSUB, United States
}

\begin{abstract}
The purpose of this paper is to examine some of the profound effects of Augmented Intelligence (AI) on Product, one of the "Four-Ps" of marketing: Product, Price, Place, and Promotion. Today's customers are used to extreme convenience, beyond the brick-and-mortar shopping experience, and beyond online images. Customers increasingly demand more information, and more personalized information. This paper addresses how the presentation of products has changed. This paper is conceptual, based on a review of academic literature on marketing strategy, psychology, AI, and Machine Learning as chronicled in major marketing and business research journals.
\end{abstract}

Keywords: artificial intelligence,augmented intelligence, machine learning discounted utility theory

\section{INTRODUCTION}

We are living in the age of the ever-connected consumer. We live in an age where consumers can access vast amounts of information and communicate with each other across the world with ease. Consumers can easily communicate with each other across the globe and the cost of searching for information is low (Stephen, A. T., 2017).

This connectivity has given marketers access to more and richer data and has increased the need for companies to leverage big data into usable market intelligence that helps them accurately target customers. The ever-connected customer is impacting all facets of marketing and brand management (Stephen, A. T., 2017).

Augmented Intelligence (AI) and Machine Learning (ML) are rapidly changing-and enhancing - traditional marketing. ML represents a key evolution in the fields of computer science, data analysis, software engineering, and AI. ML is founded on the basis that machines should be able to learn and adapt through experience (Rouse, 2017). Growing volumes of data, advances in computational processing, and affordable data storage have all contributed to a resurging interest in ML over the past five years (Attaran, M. and Deb, P., 2018).

Marketers need to access this data and personalize it to the consumer. The greater availability of connected consumer data has also enabled newer forms of digital marketing, such as precision targeting and real-time, programmatic advertising that shows personalized ads to consumers at, hopefully, the right moments in terms of place, time and intention (Andrew, T.S., 2017).

The challenge presented by needing to quickly and accurately discern what customers want and then offering it in an efficient manner requires the complete understanding of the customer, aligning the organization to better deliver enhanced value, and facilitating the immediate accessibility of information (Grossberg, K.A., 2016).

\footnotetext{
${ }^{1}$ sattaran@bryant.edu
} 
Quantitative methods and statistical techniques are being used to understand and analyze big data with descriptive, diagnostic, prescriptive, and predictive analytics. Real-time customer feedback on Product design is now available. This groundbreaking availability of data has made profound impacts on the 4 Pillars of Marketing: Product, Price, Place, and Promotion, and has changed the way they interact with each other.

ML allows marketers to precisely target their customers. The more precise the targeting, the greater the impact on customer "anticipation". Chun, Diehl, and MacInnis describe this anticipation as "Savoring" (2017). These authors go on to say, "savoring emphasizes the pleasure one feels in the present moment". Effective sales people sell the "sizzle", not the steak, meaning they engage the customer in cognitively experiencing the Product or the service that they are selling before the actual purchase, rather than simply just pushing the bare product or service at the customer. When customers can see themselves experiencing or using a product or service, they begin to anticipate the actual experience of having the product or service. At this point, customers are entering the "Desire" stage of the AIDA model (Figure 1). Once desire occurs, action (intention to purchase) is likely to follow. In this paper, we will look at some of the ways AI interacts with Product enhance the anticipatory experience.

This paper is organized in four sections. The first section discusses the rapid changes in AI and some of its influences on Product, one of the 4-Ps of Marketing. The second section discusses and gives examples of Savoring - the enhanced experience enabled by AI and Anticipation. Section three focuses on Desire, the result of savoring combined with anticipation. Section four hypothesizes that Reinforcement (when the actual experience with the purchased Product or service matches or exceeds the savored cognitive pre-purchase experience) will enhance the likelihood of future purchases as a result of the customer desiring to re-experience the entire purchase experience. These four propositions are listed below.

- P1: AI enhances the pre-purchase customer experience (savoring).

- P2: Savoring creates an experience that builds anticipation. This anticipation leads to a trust that the actual future experience with the product or service will match the present pre-purchase savored (cognitive) experience. This anticipation, combined with trust effectively creates desire.

- P3: Anticipation combined with trust (desire) increases the likelihood of purchase.

- P4: Reinforcement - when pleasure with the purchase (that is, when the actual experience with the purchased product or service matches or exceeds the savored cognitive pre-purchase experience) creates the desire to re-experience savoring and the entire purchase experience.

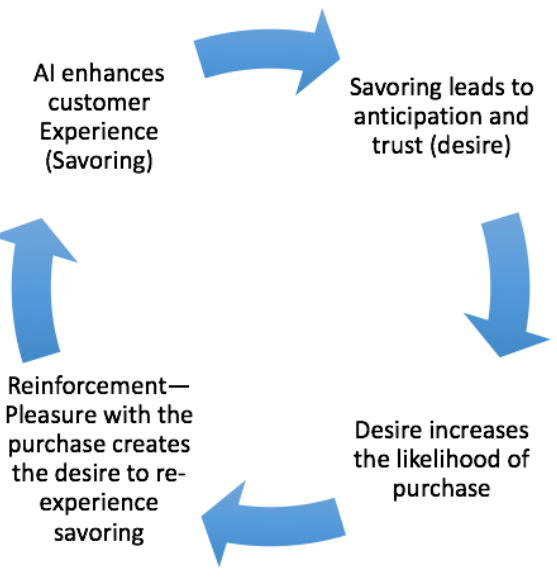

PART I: AUGMENTED INTELLIGENCE, AN INTRODUCTION 


\section{Global Fashion Management Conference at Paris}

Traditional business is undergoing major changes. We are evolving from static and passive reports of past events to proactive analytics with real-time dashboards that allow us to see what is happening in every second. The factors that have contributed to underlying shifts include large volumes of data, the Internet, the evolution to the Cloud, and the changing demands of customers. The Internet revolution has created an environment where consumers want even more information and have even greater expectations (Attaran, M., and Attaran, S., 2018).

A recent article by McAfee and Brynjolfsson published in Harvard Business Review claimed that growing numbers of companies are collecting data from their customers. Walmart collects more than 2.5 quadrillion bytes of data every hour from customer transactions. As of 2012, about 2.5 billion gigabytes of data are created every day, and that number is doubling every 40 months. By the year 2020, about 1.7 megabytes of new information will be created every second for every human being on the planet. By then, our accumulated universe of data will reach 44 trillion gigabytes (McAfee and Brynjolfsson, 2012).

Yet, in the rapidly evolving retail landscape, consumers' needs still drive their purchase decisions. Shoppers make most consumption decisions, however newer technologies such as the Internet of things and robots, and newer business models (e.g., subscription models), and big data/predictive analytics suggest that the shopping process is on the verge of a quantum leap into an entirely new shopping realm where the impact of AI is still being discovered (Grewal, D., Roggeveen, A.L., and Nordfält, J., 2017).

AI's main scope is to earn a competitive advantage within manufacturing, e-commerce, accounting, human resources, marketing, customer relations, and the like. AI-based processes tend to improve organizational performance, lower costs, increase sales, automate customer management, advance data collection and processing, save time, and limit flaws (OŃSKA, M. R., \& Polkowski, Z., 2017).

AI-based marketing can boost marketing efficiency by directing the right efforts towards the right customer. In this context, AI marketing derives a form of direct marketing which leverages the techniques of database marketing along with the AI-based concepts and models (Rekha, A. G., Abdulla, M. S., \& Asharaf, S., 2016). AI can support improving brand awareness and reinforcement, lead to higher conversion rates, advance customer service and upsell, and deliver passionate subscribers (Kose, U., \& Sert, S., 2017).

Marketers who use AI as a tool to engage their customers cognitively will benefit greatly from this explosion of data and consumer connectivity. Sections II and III of this paper detail some of the opportunities AI provides marketers on the presentation of Products as an experience.

\section{PART II: SAVORING - THE PRE-PURCHASE EXPERIENCE AND ANTICIPATION OF THE ACTUAL EXPERIENCE}

Savoring refers to positive utility derived from anticipation of future consumption, just as dread refers to negative utility resulting from contemplation of the future (Jevons, W.S., 1905). The term Savoring stems from the Discounted Utility theory (DU). In economics, discounted utility is the utility (desirability) of some future event, such as consuming a certain amount of a good, as perceived at the present time as opposed to at the time of its actual occurrence. It is calculated as the present discounted value of future utility, and for people with a time preference for sooner rather than later gratification, it is less than the future utility (Wikipedia, 2018).

A 1981 study that explicitly questioned the general applicability of positive discounting concluded that 'the case for positive time preference is absolutely compelling' (Olson, M. and Bailey, M., 1981). Time preference follows directly from the fact that there is always uncertainty about the future, so the consumer cannot be sure whether any assets acquired by saving will retain their value, nor can the consumer even know if they will be alive to enjoy the fruits resulting from saving (Olson, M. and Bailey, M., 1981). 
George Lowenstein modified DU by introducing an insight once recognized by economiststhat anticipation of the future has an impact on immediate well-being (1987). Kumar, Killingsworth, and Gilovich propose that waiting for an experience tends to be more enjoyable than waiting to receive a material good (2014). Most of the examples of savoring cited by Loewenstein (1987) involve experiences, an asymmetry that dovetails with research on experiential versus material purchases, or money spent on doing versus having. Van Boven and Gilovich (2003) found that experiences tend to produce more enduring satisfaction than do possessions.

As mentioned earlier in this paper, effective sales people engage the customer in cognitively experiencing the product or the experience that the marketer is selling in the present, with the goal of creating an anticipatory feeling for the future. In short, they sell the anticipated experience in the present, not the Product that lies in the future. Note that at this point, we are transforming Product into Experience. When customers can see themselves experiencing or using a Product, they are entering the "Desire" stage of the AIDA model (Figure 1). Once desire occurs, action is likely to follow. It is vital for marketers to maximize consumers' realtime (ongoing) anticipation and remembered enjoyment of consumption experiences (Schmitt, B., 1999). The more enjoyable such experiences are, the more likely consumers are to repeat them, thereby increasing corporate revenue, increasing the likelihood of sharing their experiences with others, and reducing corporate marketing costs (Moore, 2012).

Studies show that savoring an upcoming experience positively affects ongoing and remembered consumption enjoyment. For example, Viking River Cruises and Lindblad Expeditions encourage savoring prior to upcoming trips by sending destination-specific interactive presentations, reading lists, or language videos of useful phrases for different countries along the cruise. When people savor an upcoming consumption experience, they are aware in the moment that they feel pleasure from this upcoming experience (Chun, H. H., et. al., 2017).

Savoring an upcoming positive experience enhances consumption enjoyment of the experience while it is ongoing and retrospectively (Chun, H. H., et. al., 2017). Savoring an upcoming experience is likely to use elaborative processing that involves anticipation (Schlosser and Shavitt, 2002) and imagery processing (MacInnis and Price, 1987). Thus, savoring requires that consumers have sufficient motivation, ability, and opportunity (Greenwald and Leavitt, 1984; MacInnis and Jaworski, 1989) to engage in elaborative processing (Schacter and Addis, 2007). For example, limited knowledge of a future consumption experience or limited time or processing resources to savor the upcoming experience should limit its effect on consumption enjoyment. Furthermore, distractions during the actual experience may be detrimental to retrieving memory traces created during savoring, thus hampering the effect of prior savoring on enjoyment.

This paper theorizes that savoring leads to anticipation, which leads to trust (belief) that the actual experience in the future will match or exceed the pleasure of the cognitive/savored experience, however it must be noted that the actual experience must be as uninterrupted as possible in order for the customer to retrieve the affective memory traces of savoring. Interruption will eliminate the effect of savoring the upcoming experience (Chun, H. H., et. al., 2017). This final phase reinforces the satisfaction with the purchase experience, which then increases the likelihood of future purchases.

\section{PART III: DESIRE-THE RESULT OF USING AI AS A TOOL TO CREATE THE SAVORING EXPERIENCE}

This section of the paper discusses three companies that have effectively harnessed big data to change the way Product is presented to and experienced by customers. Technology can help 


\section{Global Fashion Management Conference at Paris}

retailers target appropriate consumers; technology also enables consumers to make better informed decisions about which products or services to consume (Grewal, D., et. al., 2017). The concept of shopping online is appealing because of its potential to deliver greater convenience, more and better product information, and lower prices (Burke, 1997). The Internet provides an inexpensive and targeted means for reaching consumers. By leveraging interactive technology, manufacturers can build one-to-one relationships with their customers, tailoring the marketing mix to individual preferences (Pine, Peppers, and Rogers, 1995).

A purchase provides the retailer a multitude of disparate information, including transactional data (e.g., price paid, quantity purchased, shopping basket composition), consumer data (e.g., gender, age, family composition), and environmental data (e.g., temperature). Retailers that can draw effective insights from big data make better predictions about consumer behavior, design more appealing offers, better target their customers, and develop tools that encourage consumers to make purchase decisions that favor their Products. Thus, big data can initiate beneficial, cyclical processes of consumer consumption and engagement that in turn leads to enhanced profitability (Grewal, D., et. al., 2017).

When much of consumers' exposure to retail assortments comes through a digital interface, visual design decisions, both in how the overall assortment is depicted and in how the individual items within the assortment are shown, will become critical for influencing consumer reactions (Khan, B.E., 2017). While such stimulus-based judgments (Lynch and Srull, 1982) are important in offline shopping, they will be particularly relevant in online shopping, because the focus is narrower (on a screen rather than at a multi-sensory physical store level), and online environments can be more attention demanding (Mosteller, Donthu, and Eroglu, 2014).

Once consumers pay attention to items within an assortment, they then have to make sense of it. Visual variables can influence the speed and accuracy of low-level processes (Schwarz, 2015). This suggests that the design elements of an assortment can make it easier for consumers to process stimuli. Processing fluency is a term that encompasses all sources that facilitate processing in any form. Research shows that increasing fluency feels good and this mildly positive affect can serve as input into judgment (Schwarz, 2015). Fluency not only increases the liking of a product but also decreases deferral (Novemsky, et al., 2007). In addition, consumers hold lay theories of mental processes and the ease or difficulty of the experience causes them to form inferences. When fluency is high, consumers feel more confident and are more likely to form positive inferences and perceptions (Schwarz, 2015). When processing is more difficult or more disfluent, processing styles shift from automatic processing to more analytic processing (Schwarz, 2015). The more analytic a customer is, the less that customer will experience savoring.

In a unique experimental design, Milosavljevic, M., Navalpakkam, V., Koch, C., and Rangel, A. (2012) found that higher liking ratings were given to stimuli at the time of choice as a function of the amount of attention that they received during the decision making process. In this study, however, consumers had previous experiences with some of the brands. When consumers had strong preferences for a particular brand, they were good at choosing that brand in rapid decision-making tasks and presumably paid more attention to those brands-perhaps not surprising. But when preferences were weak, consumers were more influenced by the visual features of the stimuli. Milosavljevic, et al., (2012) found that when brands were relatively similar, consumers ended up choosing items that were visually prominent at least $40 \%$ of the time, even when these choices were inconsistent with prior preferences.

This paper suggests that it is not just how Products are shown, it is how Products are presented that becomes the critical element in influencing consumer reactions. L'Oréal and ClothCap are leaders in presenting Products in ways that engage customers during the shopping phase and post purchase. These companies have successfully employed stimulus-based AI techniques to engage customers cognitively prior to purchase. This pre-purchase cognitive engagement is effectively, savoring. Customers are cognitively positively experiencing the Products prior to 


\section{Global Fashion Management Conference at Paris}

purchase. As mentioned earlier in this paper, this pre-purchase savoring of an upcoming positive experience enhances consumption enjoyment of the experience while it is ongoing and retrospectively (Chun, H. H., et. al., 2017).

\section{Makeup Genius}

One of the most important tasks in marketing is to create and communicate value to customers in order to drive their satisfaction, loyalty, and profitability (MSI, 2014 - 2016). In May of 2014, L'Oréal Paris launched their Makeup Genius app. This app is not just virtual; it's Augmented Reality. The vast majority of women want to try on makeup before purchasing it, which presents a major hurdle for cosmetics being sold in supermarkets. Enter Makeup Genius, an app that lets you try on makeup via your cell phone. Similar to developing a 3-D movie, special technology had to be used to ensure realistic effects. After more than seven years of research, RT Track 64 facial-tracking-algorism technology was patented, delivering the most precise facial recognition through a live mirror camera. You can move your lips and bat your lashes, and your virtual makeup will stay on (Reeder, A., 2014). Once you decide that you like what you see, you can save the look, share it with your friends, and purchase the cosmetics directly from the app (McCann Paris, 2016).

L'Oréal's Make-Up Genius liberates consumers by allowing them to try before they buy and importantly, allows L'Oréal to upsell and actively market a broad selection of ranges. L'Oréal was able to use data to deliver ever more relevant communication to consumers - so, if they know you have been looking at "smoky eyes", they inform you of more products to create smoky eyes. If a customer shares a photo of their look via the app, or if they make a purchase, L'Oréal receives information about customer interest and sentiment about their product that they otherwise would not have access to (Stephen, A. T., 2017).

Makeup Genius was a big success. In the first year, when the app was available only in the United States, France, and China, it was downloaded approximately 5.9 million times. After two years, with the app available throughout much of the world, it had been downloaded about 16.3 million times and the average user tried on 18 different Products. Kumar, V., and Reinartz, W., (2016) propose that sustainable businesses must create value for customers and also extract some of that customer value in the form of profit, thereby creating value for the firm. Today, 10 percent of L'Oréal's sales are in China, thanks to the Makeup Genius app. A newer version of the app is available today. It continues to be a popular digital touchpoint for L'Oréal Paris and the brand sees it as an important digital platform for connecting and interacting with consumers (Stephen, A.T. 2017).

L'Oréal Paris' digital strategy, which combines driving sales with boosting front-of-mind awareness, is:

- Based on a strong consumer insight

- Fulfilling a genuine consumer need, creating real value

- A long term proposition for both the consumer and brand

- Aligned to a strategic business goal

- Can be deployed across dozens of markets

- Fuels a CRM (Customer Relationship Management) program (Copyright (C2000-

2018 Digital Strategy Consulting Limited ).

\section{D Printing}

The technology for 3D printing has roots that go back decades. The minds behind it were visionary. However, for many years, 3D printing appeared - at least in the mainstream viewto be more of a novelty than a practical tool to advance commercial manufacturing. 3D printers created one-off trinkets, souvenirs, and not much else. Business leaders were skeptical that 3D printing would ever advance enough to be an integral part of manufacturing (Wohlers, T., 2015). All of that has changed. The use of $3 \mathrm{D}$ printing for component production grew from virtually zero in 2003 to 43 percent $(\$ 1.8 \mathrm{~B})$ of global 3D-printed product and service revenue in 2014 


\section{Global Fashion Management Conference at Paris}

(Wohlers, T., 2015). Today, even skin can be 3D printed (Montablano, E., 2018). 3D printing is leading the way to optimized Product and reduced manufacturing and inventory costs.

Though its explorations are in the very early stages, clothing brand and global manufacturer Levi Strauss \& Co. is positioning itself to become one of the first off-the-shelf clothing companies to explore the use of 3D printing to fabricate its products. Levi's Head of Global Product Innovation Paul Dillinger joined with the publication Fast Company at the Autodesk Pier 9 Workshop in San Francisco to create the renderings and demonstrate Levi's experimentation with 3D digital designing and manufacturing. Levi's goal is to use 3D printing to cut back on both material (inventory) and manufacturing costs (Montalbano, E., (2018).

Logically, this custom manufacturing could extend to any wearable garment, including shoes and millinery. Future implications of 3D clothing printing impact both Product and Place. If the producer has your physical measurements, theoretically, you could order custom couture online and either pick up the perfectly fitting garment, or have it shipped directly to you.

\section{Virtual Try-Ons}

Another AI intervention into the garment industry gives customers the ability to try on clothing virtually. This process relies on a $2 \mathrm{D}$ clothing pattern from a manufacturer and simulates how it might fit on your body (Krishna, S., 2017). Unfortunately, his 2D effect is similar to putting a paper dress on a paper doll; depth and dimensions are ignored, thereby leaving the customer with a less than satisfactory rendition of how the garment will actually look on them. This look is comparable to holding a cardboard cutout of the garment in front of yourself while looking in a mirror. Left out of this equation are the hand and drape of the fabric. The hand of a fabric refers to the "feel" of the fabric against your skin. There are many adjectives that can be used to describe the hand, or feel, of a fabric - words such as cool, slick, smooth, loose, stiff, heavy, and stretchy can all be used to describe the hand of a fabric. The drape of a fabric describes how the fabric behaves with gravity. If the fabric is cut on a bias, it will hang differently than if the fabric is cut on the grainline or the crossgrain. A woven fabric will hang differently than a knit fabric, and so on. Without accurate renditions of the body wearing the garment and of the fabric that the garment is made of, the current virtual try-ons yield less than optimal results.

ClothCap, a seamless 4D data-driven clothing capture approach, is tackling this issue. ClothCap captures dynamic clothing on humans from 4D scans and transforms these "captures" to more easily dress virtual avatars (Pons-Moll, G., Pujades, S., Hu, S., and Black, M.J., 2017). It uses 4D movies, recorded using a scanner with 66 cameras and projectors to take full stock of the person being scanned. This allows the scanner to fully see how clothing drapes on a person's body and where it wrinkles. It also records how a body moves under the clothes and how the garment shifts accordingly (reference Figures $2-5$ ). Once this data is analyzed, it's easy to separate the piece of clothing from the original body and use it in very realistic virtual try-ons (Krishna, S., (2017).

While ClothCap's techniques may seem innovative and novel, it must be remembered that this "experiencing" of the fit and fall of the garment is a significant part of "savoring". When customers can see themselves in a garment, and if the experience is positive, they are setting up anticipation which is a precursor of desire, and therefore a precursor of Purchasing.

\section{PART IV: REINFORCEMENT_POST PURCHASE SATISFACTION}

In modern, multifaceted, omnichannel environments, consumers are bombarded with information about goods and services. Retailers that can connect with their customers by providing targeted information and offering value, stand apart and have the potential to create deep customer engagement (Grewal, D., et. al., 2017). 


\section{Global Fashion Management Conference at Paris}

Chun, H. H., et. al. (2017) postulate that if savoring creates affective memory traces that are subsequently retrieved and integrated into the actual consumption experience, savoring should enhance not just remembered but also actual consumption enjoyment (2017). They also find that savoring an upcoming experience causes memory traces of pleasure from the savored experience to be reactivated and integrated into both the ongoing and remembered consumption experience. This also implies that the effect of savoring on enjoyment should endure over time, unlike short-lived mood and mindset explanations.

As mentioned in section three of this paper, George Lowenstein modified DU by introducing an insight once recognized by economists - that anticipation of the future has an impact on immediate wellbeing (1987). Kumar, Killingsworth, and Gilovich propose that waiting for an experience tends to be more enjoyable than waiting to receive a material good (2014). It is at this point where we emphasize turning the Product (anticipation) into an experience.

Per Bentham (1970), utility refers to the pleasures and pains that derive from anticipation. The more "vivid" and "imaginable" the savored experience, the greater the utility of the savored (or dreaded) experience (Lowenstein, G., 1987). Producers that give their customers a vivid and engaged experience of savoring their product or service, will benefit from those customers' remembered consumption enjoyment after the product or service has been consumed. That is, these companies will benefit from their customers remembered savored experiences, and thereby the greatly enhanced likelihood that their customers will seek a similarly satisfactory shopping experience from said companies in the future. It must however be remembered that the actual experience of the product or service must be as uninterrupted as possible in order to maximize the customers' remembered consumption enjoyment after the Product or service has been consumed. How this final factor will be managed is an area for future research.

\section{CONCLUSION：MEASURING SAVORING AN UPCOMING EXPERIENCE}

Chun, Diehl, and MacInnis (2017) ran five studies to measure savoring an upcoming experience. They reviewed companies such as Walt Disney World Resort Hotels, which routinely distributes multiple upcoming trip reminders before consumers arrive on site (e.g., "Your Disney experience starts right now!"). Prior research has suggested that such reminders make waiting times less painful (Lowenstein, G., 1987). Chun, H. H., et. al. were interested in whether such reminders also enhance both ongoing and remembered enjoyment of the consumption experience. They suggest that reminders that encourage savoring of an upcoming experience should enhance opportunities for consumers to be aware of and encode their current state of pleasure from contemplating the upcoming experience. Such processing should, in turn, make memory traces more accessible when the consumption experience unfolds in real time and when it is remembered (decoded).

This paper discussed rapid changes in AI and some of its influences on Product, one of the 4Ps of Marketing, gave examples of Savoring - the enhanced experience enabled by $A I$ and Anticipation, discussed Desire, the result of savoring combined with anticipation and hypothesized that Reinforcement (when the actual experience with the purchased Product or service matches or exceeds the savored cognitive pre-purchase experience) will enhance the likelihood of future purchases as a result of the customer desiring to re-experience the entire purchase experience.

This paper concludes that using AI to create an anticipatory experience of a Product or Service that has yet to be purchased or experienced will create a savoring experience that will (a) greatly increase the likelihood to purchase in the future, (b) greatly enhance ongoing and remembered enjoyment of said Product or Service, and (c) greatly increase the likelihood of repeat purchases in the future, as long as the actual Product or service experience is relatively uninterrupted. The more enjoyable such experiences are, the more likely consumers are to repeat them, thereby increasing corporate revenue, and to share their experiences with others, thereby reducing marketing costs (Moore, 2012). 


\section{Global Fashion Management Conference at Paris}

\section{REFERENCES}

Andrew, T. S. (2017). Here Comes the Hyper-Connected Augmented Consumer. Gfk MIR, Vol. 9, No. 2.

Attaran, M., \& Attaran, S. (2018). The Rise of Embedded Analytics: Empowering Manufacturing and Service Industry With Big Data. International Journal of Business Intelligence Research (IJBIR), 9(1), 16-37.

Bentham, J. (I970). Introduction to the Principles and Morals of Legislation (1789). London: Athlone Press.

Burke, R. R. (1997). Do you see what I see? The future of virtual shopping. Journal of the Academy of Marketing Science, 25(4), 352-360.

Chun, H.H., Diehl, K., and MacInnis, D.J. (2017). Savoring an Upcoming Experience Affects Ongoing and Remembered Consumption Enjoyment. Journal of Marketing, 81 (3), 96110

Dholakia, S. (2015). Designing a marketing organization for the digital age. Harvard Business Review Analytic Services Report.

Greenwald, A. G., \& Leavitt, C. (1984). Audience Involvement in Advertising: Four Levels. Journal of Consumer research, 11(1), 581-592.

Grewal, D., Roggeveen, A. L., \& Nordfält, J., (2017). The future of retailing. Journal of Retailing, 93(1), 1-6.

Grossberg, K. A. (2016). The New Marketing Solutions That Will Drive Strategy Implementation. Strategy \& leadership, 44(3), 20-26.

Jabłońska, M. R., \& Polkowski, Z. (2017). Artificial Intelligence-Based Processes in SMES. Studia i Materialy Polskiego Stowarzyszenia Zarzadzania Wiedza/Studies \& Proceedings Polish Association for Knowledge Management, (86).

Jevons, W. S. (1905). Essays on Economics. London: Macmillan.

Kahn, B. E. (2017). Using Visual Design to Improve Customer Perceptions of Online Assortments. Journal of retailing, 93(1), 29-42.

Kose, U., \& Sert, S. (2017). Improving Content Marketing Processes With the Approaches by Artificial Intelligence. arXiv preprint arXiv:1704.02114.

Kumar, A., Killingsworth, M. A., \& Gilovich, T. (2014). Waiting for Merlot: Anticipatory Consumption of Experiential and Material Purchases. Psychological science, 25(10), 1924-1931.

Kumar, V., \& Reinartz, W. (2016). Creating Enduring Customer Value. Journal of Marketing, 80(6), 36-68.

Loewenstein, G. (1987). Anticipation and the Valuation of Delayed Consumption. The Economic Journal, 97(387), 666-684.

Lynch Jr, J. G., \& Srull, T. K. (1982). Memory and Attentional Factors in Consumer Choice: Concepts and Research Methods. Journal of Consumer Research, 9(1), 18-37.

Marketing Science Institute (2014m- 2016). Retrieved from http://www.msi.org/uploads/files/MSI_RP14-16.pdf

McAfee, A., Brynjolfsson, E., Davenport, T. H., Patil, D. J., \& Barton, D. (2012). Big data: the management revolution. Harvard business review, 90(10), 60-68.

McCann Paris (2016). Makeup Genius - L'Oréal Paris Case Study. Retrieved from https://www.youtube.com/watch?v=R5OnjiDa71s .

Maclnnis, D. J., \& Jaworski, B. J. (1989). Information Processing From Advertisements: Toward an Integrative Framework. The Journal of Marketing, 1-23

MacInnis, D. J., \& Price, L. L. (1987). The Role of Imagery in Information Processing: Review and Extensions. Journal of Consumer Research, 13(4), 473-491.

Milosavljevic, M., Navalpakkam, V., Koch, C., \& Rangel, A. (2012). Relative Visual Saliency Differences Induce Sizable Bias in Consumer Choice. Journal of Consumer Psychology, 22(1), 67-74.

Montablano, E., (2018). 3D Printing Ligaments and Tendons. Materials \& Assembly, 
November 16, 2018. Retrieved from https://www.designnews.com/materials-assembly/3dprinting-ligaments-and-tendons/85151707159712

Mosteller, J., Donthu, N., \& Eroglu, S. (2014). The Fluent Online Shopping Experience. Journal of Business Research, 67(11), 2486-2493

Moore, Sarah G. (2012). Some Things Are Better Left Unsaid: How Word of Mouth Influences the Storyteller. Journal of Consumer Research, 38 (6), 1140-54.

Novemsky, N., Dhar, R., Schwarz, N., \& Simonson, I. (2007). Preference Fluency in Choice. Journal of Marketing Research, 44(3), 347-356.

Olson, M., \& Bailey, M. J. (1981). Positive Time Preference. Journal of Political Economy, 89(1), 1-25.

Perrault Jr., W. D., Cannon, J. P., \& McCarthy, E. J. (2014). Essentials of Marketing: A Strategy Planning Approach. New York, NY: McGraw-Hill Irwin.

Pine, B. J., Peppers, D., \& Rogers, M. (2009). Do You Want to Keep Your Customers Forever? Harvard Business Press.

Pons-Moll, G., Pujades, S., Hu, S., and Black, M. J. (2017). Clothcap: Seamless 4D Clothing Capture and Retargeting. ACM Transactions on Graphics (TOG), 36(4), 73.

Rekha, A. G., Abdulla, M. S., \& Asharaf, S. (2016). Artificial Intelligence Marketing: An Application of a Novel Lightly Trained Support Vector Data Description. Journal of Information and Optimization Sciences, 37(5), 681-691.

Rouse, M. (2017). Machine Learning. Whatis.com [online]. Retrieved from http://whatis.techtarget.com/definition/ machine-learning (accessed 10 February 2018).

Schacter, D. L., \& Addis, D. R. (2007). Constructive memory: the ghosts of past and future. Nature, 445(7123), 27.

Schlosser, A. E., \& Shavitt, S. (2002). Anticipating Discussion About a Product: Rehearsing What to Say Can Affect Your Judgments. Journal of Consumer Research, 29(1), 101115.

Schmitt, Bernd (1999). Experiential Marketing. Journal of Marketing Management, 15 (1-3), 53-67.

Wikipedia, 2018. Retrieved from https://en.wikipedia.org/wiki/Discounted_utility

Wohlers, T., (2014). 3D Printing and Additive Manufacturing State of the Industry. Annual Worldwide Progress Report. Wohlers Associates.

Figure 1

\begin{tabular}{|l|l|l|}
\hline \multicolumn{1}{|c|}{ Promotion Objectives } & \multicolumn{1}{|c|}{ Adoption Process } & \multicolumn{1}{c|}{ AlDA Model } \\
\hline Informing & $\begin{array}{l}\text { Awareness } \\
\text { Interest }\end{array}$ & $\begin{array}{l}\text { Attention } \\
\text { Interest }\end{array}$ \\
\hline Persuading & $\begin{array}{l}\text { Evaluation } \\
\text { Trial }\end{array}$ & Desire \\
\hline Reminding & $\begin{array}{l}\text { Decision } \\
\text { Confirmation }\end{array}$ & Action \\
\hline
\end{tabular}

(Perreault, Jr., W.D, Cannon, J.P., McCarthy, E.J., 2014) 
Figure 2

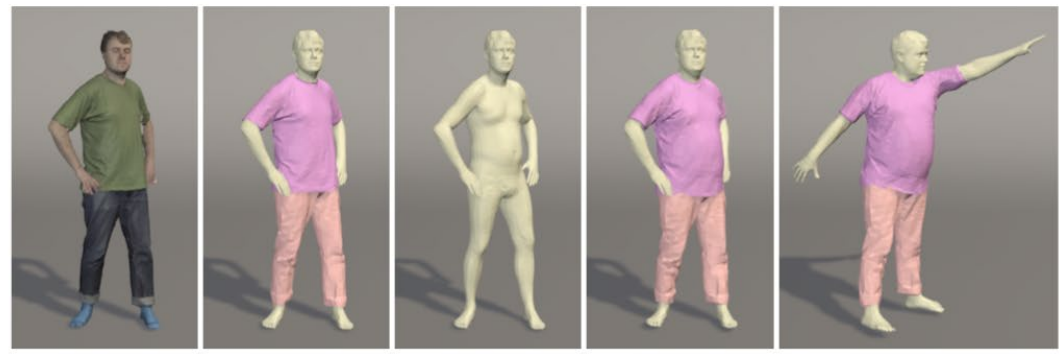

Fig. 1. ClothCap. From left to right: (1) An example 3D textured scan that is part of a 4D sequence. (2) Our multi-part aligned mesh model, layered over the body. (3) The estimated minimally clothed shape (MCS) under the clothing. (4) The body made fatter and dressed in the same clothing. Note that the clothing adapts in a natural way to the new body shape. (5) This new body shape posed in a new, never seen, pose. This illustrates how ClothCap supports a range of applications related to clothing capture, modeling, retargeting, reposing, and try-on.

(Pons-Moll, G., Pujades, S., Hu, S., and Black, M. J., 2017)

\section{Figure 3}

(Pons-Moll, G., Pujades, S., Hu, S., and Black, M. J., 2017)

\section{Figure 4}
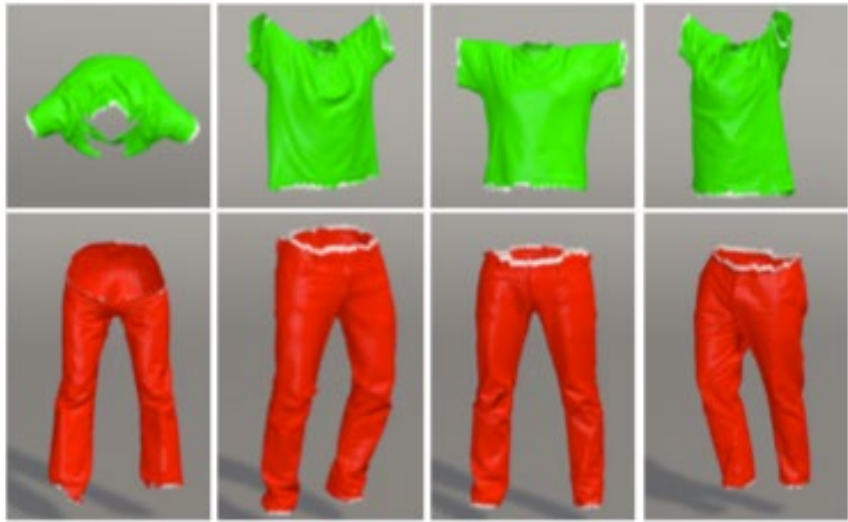

Fig. 7. Segmentation results: rows of scan geometry segmentations, shirt (top row), pants (bottom row). After solving the discrete MRF on the body topology we propagate the obtained labels back to the scan. This results in segmented scans $\mathcal{S}_{k}$. Boundaries (shown in white) can be easily identified and are propagated to the scans. Such labels provide important informa tion for the multi-cloth alignment step. They allow ClothCap to estimate consistent geometry with smooth boundaries.
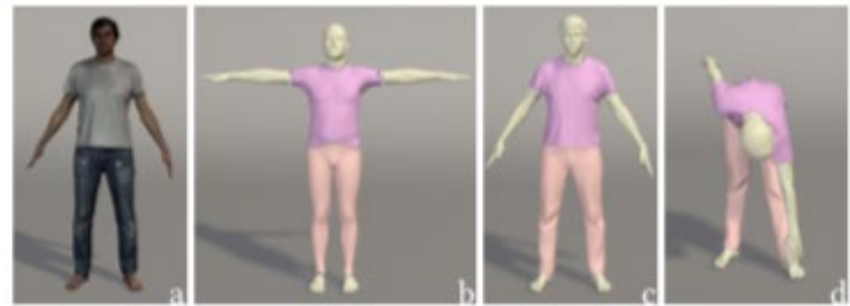

Fig. 8. Multi-cloth template extraction. Using the segmentation labels on the alignment for the first frame we break the mean shape body into a segmented cloth template (b). The segmented cloth template is then deformed to explain each cloth piece and the skin of the first frame scan (a). This results in the multi-cloth template (c). Since every vertex of the multi-cloth template is associated with one body model vertex, we can easily repose it (d) using SMPL. This reposing is critical for tracking the garments ac curately over time. The extracted multi-cloth template is used to register all the dynamic sequences. In this way we align all scans to a common template. 

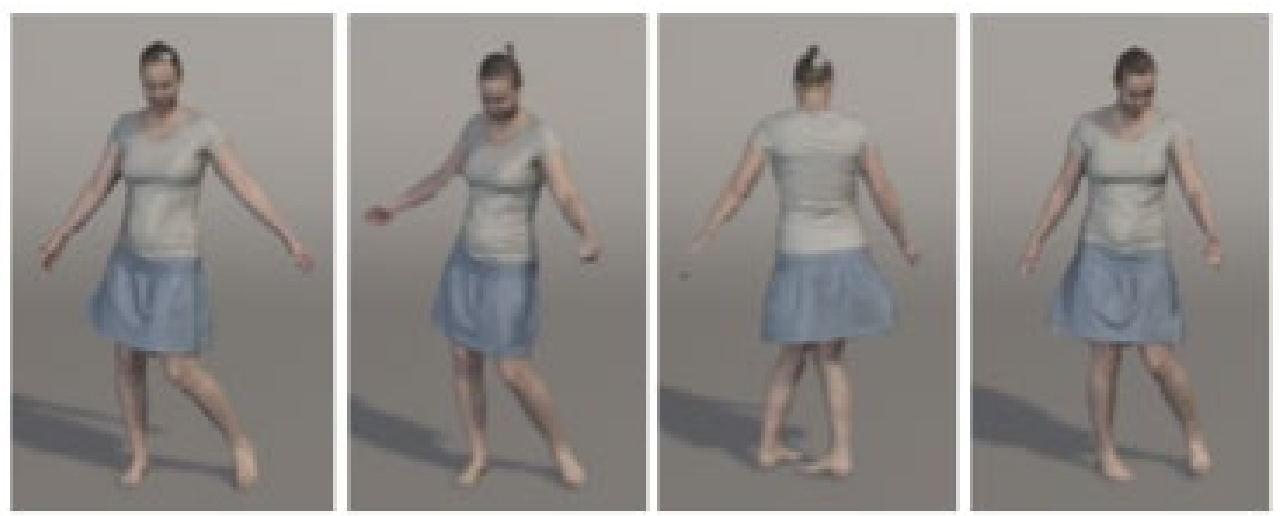

(Pons-Moll, G., Pujades, S., Hu, S., and Black, M. J., 2017)

\section{Figure 5}
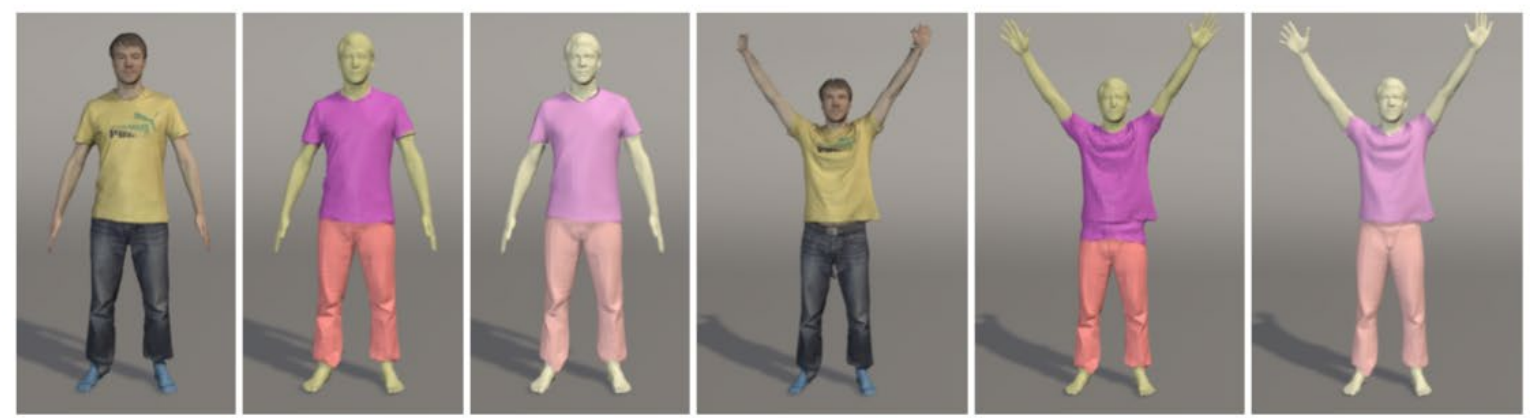

Fig. 5. The relevance of a multi-cloth model. We show 2 triplets with: scan, single-mesh alignment and multi-cloth alignment. The first frame is accurately segmented by both Steps, but in a later frame, the single mesh alignment can not accurately track the garment. The t-shirt (in lavender) is explained by the wrong set of vertices. The single-mesh alignment could be improved using an appearance based term. However, a single mesh is not able to model the gap between the trousers and the $\mathrm{t}$-shirt. Using a different mesh to track each garment better matches the physical situation.

(Pons-Moll, G., Pujades, S., Hu, S., and Black, M. J., 2017) 